(C2019, Elsevier. Licensed under the Creative Commons Attribution-NonCommercialNoDerivatives 4.0 International http://creativecommons.org/about/downloads

cc) 


\title{
Influence of Low Velocity Impact on Oxidation Performance of SiC coated C/SiC Composites
}

\author{
Leijiang $\mathrm{Yao}^{\mathrm{a},{ }^{*}}$, Peng Lyu ${ }^{\mathrm{b}, \mathrm{c}}$, Guodong Bai ${ }^{\mathrm{b}}$, Andy T. Augousti ${ }^{\mathrm{d}}$ \\ a. Laboratory of Science and Technology on UAV, Northwestern Polytechnical University, Xi'an 710065, China \\ b. School of Aeronautics, Northwestern Polytechnical University, Xi'an 710072, China \\ c. Academy of Space Electronics Information Technology, Xi'an 710100, China \\ d. Faculty of Science, Engineering and Computing, Kingston University London, SW15 3DW UK
}

\begin{abstract}
Dropped-weight impact tests were carried out to investigate the coating damage behavior of $\mathrm{SiC}$ coated plainwoven $\mathrm{C} / \mathrm{SiC}$ composites under low velocity impact (LVI). The oxidation performance after impact was evaluated in a wet oxygen environment. The relationships between coating damage area, oxidizing weight loss and the flexural strength after oxidation with the impact energy were analyzed. It was concluded from the test results that $0.5 \mathrm{~J}$ was the impact energy corresponding to damage initiation of the coating, where the oxidation loss was $2.49 \%$ and the strength retention ratio was $94.92 \%$, almost the same as the untreated coating. Between $0.5 \mathrm{~J}$ and $2 \mathrm{~J}$, the weight loss of oxidation increased with impact energy, and the oxidation mechanism gradually changed from a diffusion-controlled local oxidation to a reaction-controlled uniform oxidation. When the impact energy was larger than $2 \mathrm{~J}$, although the coating damage still increased with impact energy, weight loss and residual flexural strength remained almost constant. The residual strength remaining was no more than $8 \%$ of the non-oxidized $\mathrm{C} / \mathrm{SiC}$, indicating that the coating totally loses its anti-oxidation function.
\end{abstract}

Keywords: $\mathrm{C} / \mathrm{SiC}$ composites; Low velocity impact; Coating; Oxidation; Flexural strength

\section{Introduction}

Continuous carbon fiber reinforced silicon carbide matrix composites $(\mathrm{C} / \mathrm{SiC})$ exhibit excellent mechanical properties at elevated temperature and are considered as one of the promising candidate materials for hot structures in gas turbine engines, re-entry aerospace vehicles, and the like [1-3]. To protect carbon phases from oxidizing at high temperature, many kinds of seal coatings have been developed, in which a SiC coating obtained by chemical vapor deposition (CVD) is widely used [4-6]. However, since the thermal expansion mismatch between the seal coating and the fiber/matrix substrate always introduces microcracks in the sealing coating on cooling from the processing temperature, oxidation is apt to occur by the oxidizing atmosphere diffusing through these microcracks. Therefore, the oxidation mechanism and behavior of $\mathrm{C} / \mathrm{SiC}$ composites with seal coatings has been extensively studied [7-10]. Well deposited $\mathrm{SiC}$ coatings show an excellent anti-oxidation effect.

However, previous studies are mainly oriented towards the oxidation behavior of $\mathrm{C} / \mathrm{SiC}$ with an original intact coating. In fact, possible low velocity impact under maintained or operating conditions probably produces coating cracks or exfoliation, as well as internal delamination and cracking, since the $\mathrm{SiC}$ coating and matrix are brittle and unable to absorb the impact energy by plastic deformation as metals do. That means low velocity impact will affect the ceramic matrix composites in two ways: (a) internal cracking and delamination leads to degradation of mechanical properties, especially the compressive performance; (b) the function of the coating may exhibit significant degradation after a low velocity impact and consequently give rise to severe degradation with regard to oxidation performance. The LVI damage and its influence on the mechanical properties of CMC has been of wide concern [11-17], while the second aspect affected by LVI is seldom reported.

The present study focuses on LVI damage characteristics in coating and post-impact oxidation behavior of plainwoven $\mathrm{C} / \mathrm{SiC}$ composites protected by a CVD-SiC coating. The area of the cracked or exfoliated coating and the mass loss are used to characterize the LVI damage and post-impact oxidation behavior, respectively. The change of flexural strength after oxidation is also investigated. The effect of impact energy on the coating damage, post-impact oxidation 
performance and flexural strength is analyzed to supply an evaluation of $\mathrm{C} / \mathrm{SiC}$ subjected to low velocity impact.

\section{Experimental}

\subsection{Fabrication of specimens}

A two-dimensional $\mathrm{C} / \mathrm{SiC}$ composite was prepared by chemical vapor infiltration (CVI). The preform was laid up with plain-woven $\mathrm{T} 300^{\mathrm{TM}}$ (Toray, Japan) carbon fiber cloths. The fiber volume content was about $40 \%$. Pyrolytic carbon (PyC) interphase was deposited using butane as a precursor at $960^{\circ} \mathrm{C}$. The thickness of the PyC layer was controlled to be $200 \mathrm{~nm}$. The $\mathrm{SiC}$ matrix was deposited using methyltrichlorosilane (MTS) as a precursor and $\mathrm{H}_{2}$ as the carrying and dilute gas. The deposition temperature for $\mathrm{SiC}$ matrix is $1000^{\circ} \mathrm{C}$. The composite was then machined to form rectangular specimens with a size of $45 \mathrm{~mm} \times 32 \mathrm{~mm} \times 3 \mathrm{~mm}$. The specimens were finally coated with two layers of $\mathrm{SiC}$ using chemical vapor deposition (CVD). The deposition conditions for the $\mathrm{SiC}$ coating were the same as that of the $\mathrm{SiC}$ matrix. The detailed preparation process can be found elsewhere [7].

\subsection{Impact tests and coating damage evaluation}

Low velocity impacts were conducted on a drop-hammer impact machine. The machine was equipped with an automatic control system to prevent secondary impact. The specimens were constrained along all four edges. The weight and diameter of the steel impactor were $1.667 \mathrm{~kg}$ and $20 \mathrm{~mm}$, respectively. Impact tests for six energy levels, which were $0.5 \mathrm{~J}, 1 \mathrm{~J}, 2 \mathrm{~J}, 3 \mathrm{~J}, 4 \mathrm{~J}$ and $5 \mathrm{~J}$, were conducted by dropping the impactor from different heights $h$. The height $h$ was calculated using the following equation:

$$
h=\frac{W}{M g}
$$

where $W$ is the impact energy, $M$ is the weight of the impactor, and $g$ is the acceleration of gravity.

Only coating damage was considered, since it provides for the entrance of corrosive gas into the interior region of the samples and then affects the oxidation performance. An optical video microscope (UNION DZ3) was used to conduct surface examination of samples after impact. The damage areas in the coating on both the front and back sides were measured using digital photographs recorded by the optical video microscope. The total damage area is defined to be the sum of the damage area on both the front and the back sides.

\subsection{Oxidation tests after impact}

Isothermal oxidation tests of all the as received and impacted specimens were conducted in a wet oxygen environment. The test system is shown in Figure 1. C/SiC specimens were heated to $1300^{\circ} \mathrm{C}$ in a silicon-molybdenum resistance furnace. A flow atmosphere consisting of an oxygen-water vapor mixture at atmospheric pressure was imported into the furnace at the same time. The partial pressures of oxygen and water vapor were both $0.5 \mathrm{~atm}$. The total oxidation time was 10 hours. Specimens were separately weighed before and after oxidized for a fixed time using an electronic balance with a sensitivity of $0.1 \mathrm{mg}$. Before weighing, the specimens were dried. Then the rate of mass loss $\Delta m$ was defined to be

$$
\Delta m=\frac{\left(m_{0}-m_{\mathrm{t}}\right)}{m_{0}} \times 100 \%
$$

where $m_{0}$ is the weight before oxidation and $\mathrm{m}_{t}$ is the weight after being oxidized for $t$ hours. For comparison, an oxidation test for uncoated $\mathrm{C} / \mathrm{SiC}$ was also conducted under the same conditions. 


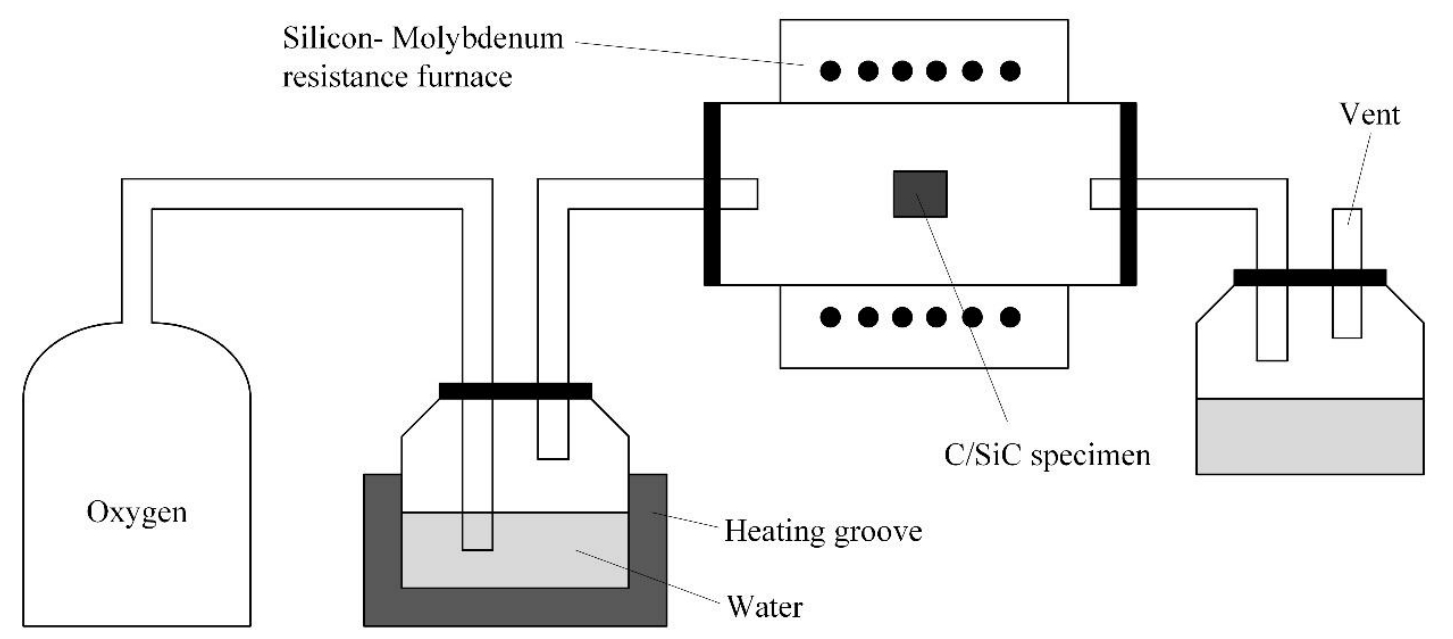

Fig. 1. Oxidation test system.

\subsection{Flexural Tests after Oxidation}

The flexural strengths of the oxidized specimens were measured by a three-point bending method at room temperature using an Instron material test machine, with a crosshead speed of $0.5 \mathrm{~mm} / \mathrm{min}$ and a span of $36 \mathrm{~mm}$. Load-displacement curves were recorded, and the flexural strength was calculated according to the following equation:

$$
\sigma_{f}=\frac{3 F L}{2 W h^{2}}
$$

where $F$ is the maximum flexural load, $L$ is the span dimension, and $W$ and $h$ are the width and thickness of the specimen respectively. After flexural tests, the fracture surfaces were observed with a scanning electron microscope (SEM, JEOL JXA-840). The flexural strength of non-oxidized $\mathrm{C} / \mathrm{SiC}$ was also tested using the same method. Then the strength retention ratio of oxidized specimens was defined to be

$$
R=\frac{\sigma_{f}}{\sigma_{f 0}} \times 100 \%
$$

Where $R$ is the strength retention ratio and $\sigma_{f 0}$ is the flexural strength of non-oxidized $\mathrm{C} / \mathrm{SiC}$.

\section{Results and discussion}

\subsection{Micro-morphologies of the as-received C/SiC specimen}

Figure 2 shows the micro-morphologies of the $\mathrm{C} / \mathrm{SiC}$ specimen. The $\mathrm{C} / \mathrm{SiC}$ substrate is covered by two thin layers of CVD-SiC coating (Fig.2 (a)). The thickness of each layer is around $20 \mu \mathrm{m}$. The coating is dense, and no visible surface damage can be observed (Fig.2 (b)), except some micro-cracks (Fig.2 (c)). These narrow coating cracks are generated during the preparation cooling process due to the thermal mismatch between the coating and the substrates, and they provide a diffusive path for the oxidizing atmosphere.
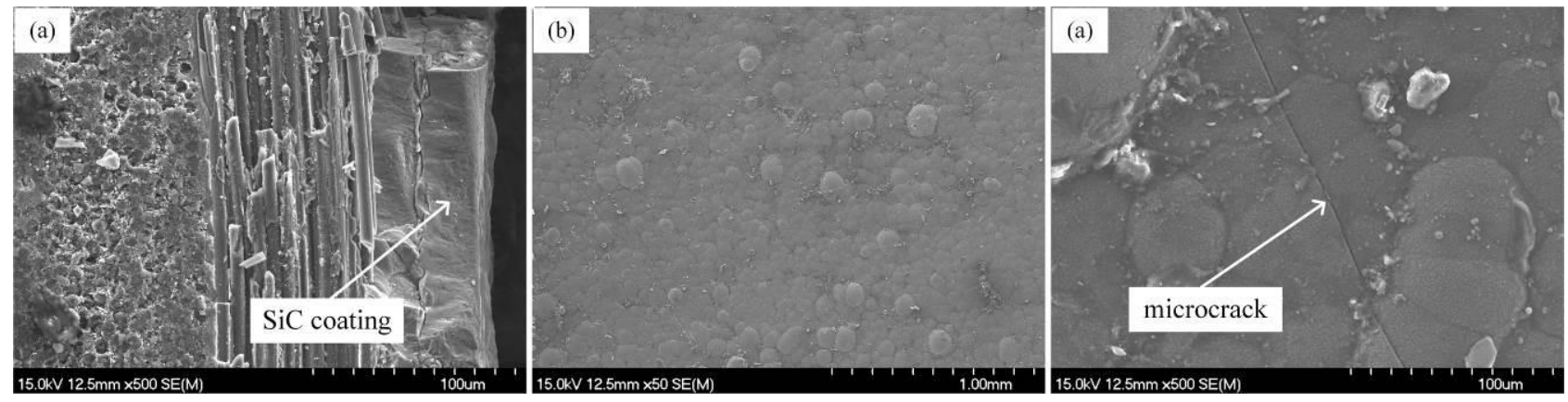

Fig. 2. SEM morphologies of as-received plain-woven $\mathrm{C} / \mathrm{SiC}$ (a) cross-section; (b) surface of CVD-SiC coating; (c) coating microcrack.

\subsection{Coating damage induced by LVI}


Surface photos of the $\mathrm{C} / \mathrm{SiC}$ specimen after impact at various energy levels are shown in Figure 3 . Both the front and back sides facing the impact were recorded. Impact-induced damage is not found in the supporting positions. In the case of an impact energy of $0.5 \mathrm{~J}$, there was no impact coating damage found on either side. When the impact energy increases to $1.0 \mathrm{~J}$, some white spots were found in the impacting area on the front side, probably caused by friction between the impactor head and the coating. There was still no coating damage identified on the back side. Then, with increasing impact energy, obvious coating damage could be identified on both sides. A circular pit was formed on the front side, and on the back side, some related damage appeared. Cracks and exfoliation could easily be observed.
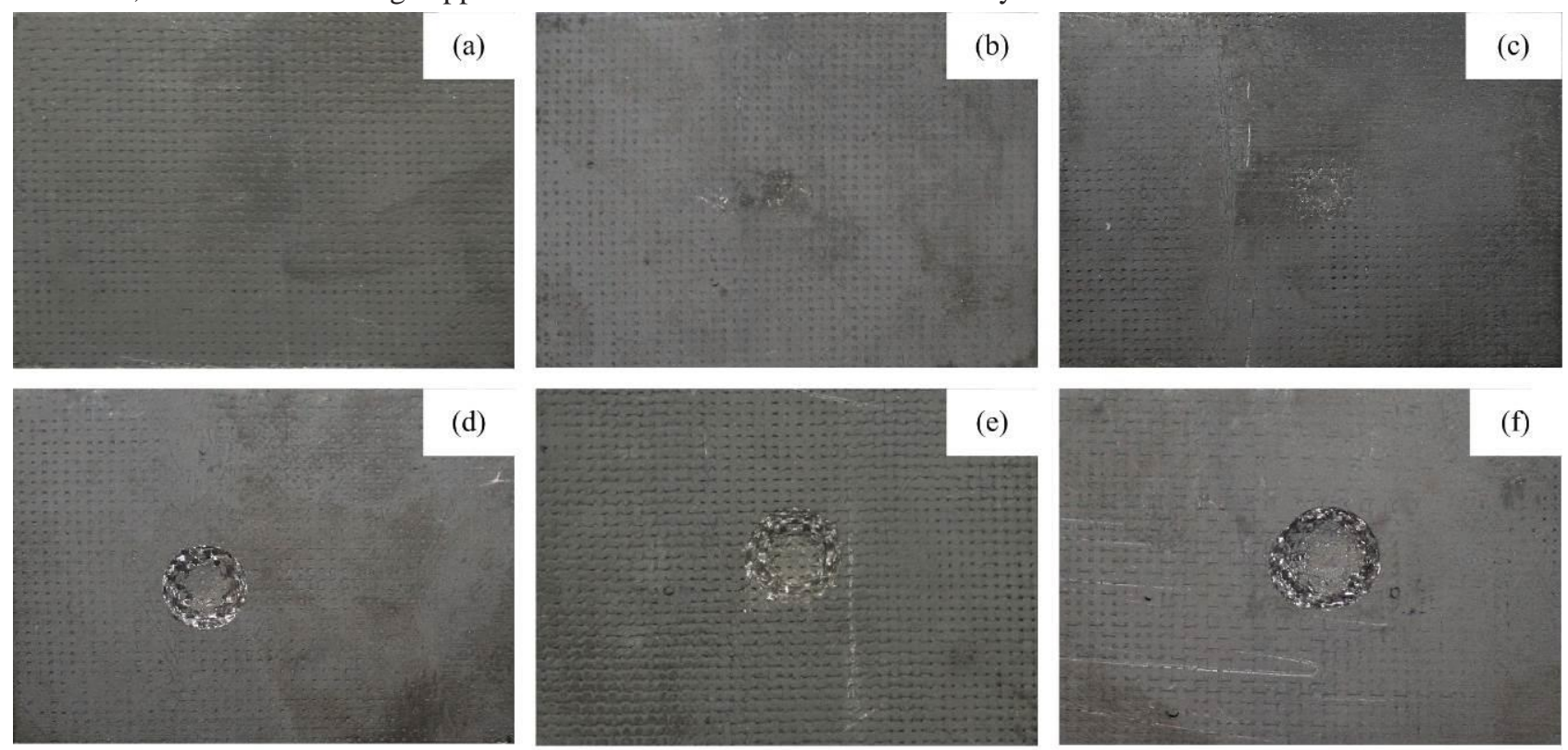

front side of impact
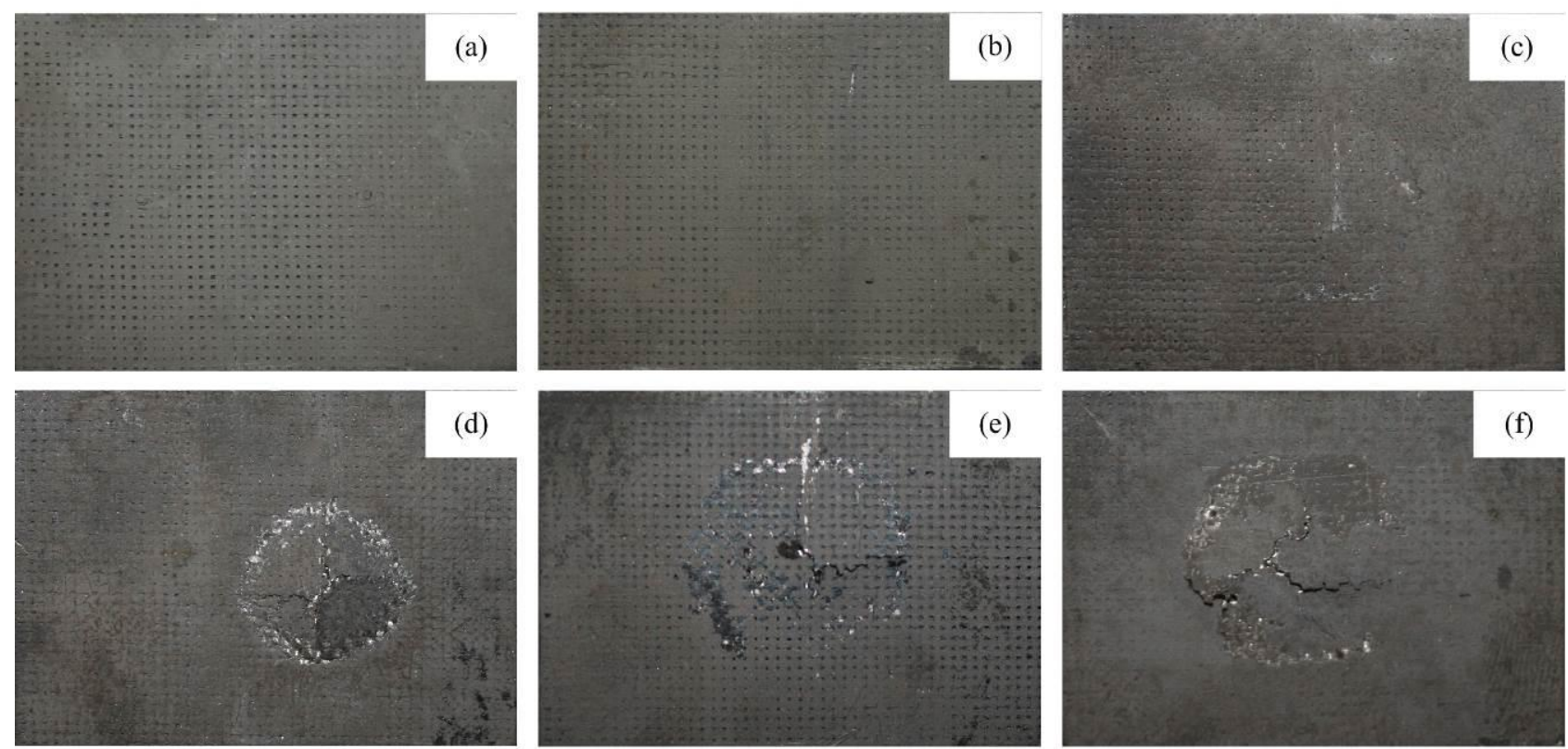

back side of impact

Fig.3. Optical photographs of the 2D-C/SiC specimens after impact at various energy levels: (a) 0.5J, (b) 1.0J, (c) 2.0J, (d) 3.0J, (e) $4.0 \mathrm{~J}$, (f) $5.0 \mathrm{~J}$.

Fig. 4 compares the coating damage in the impact area after an impact of low energy (1.0J) and high energy (5.0J), using optical microscopic photography. In the case of the lower energy impact, there were a few cracks and local exfoliation on the front side, but no damage occurs on the back side, whereas in the case of higher energy impact, the 
coating is badly destroyed on both sides. A large area of coating exfoliates from the substrates, fibers are exposed with some of them being broken.

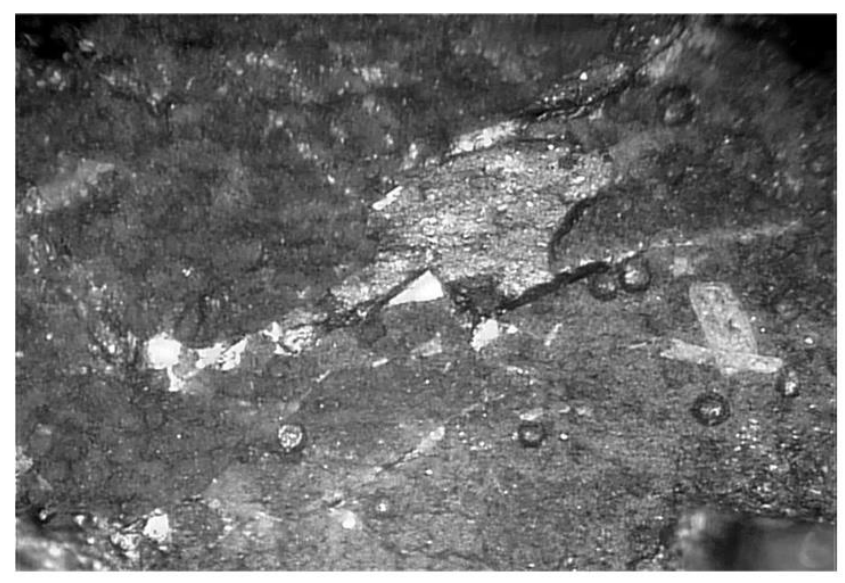

front side

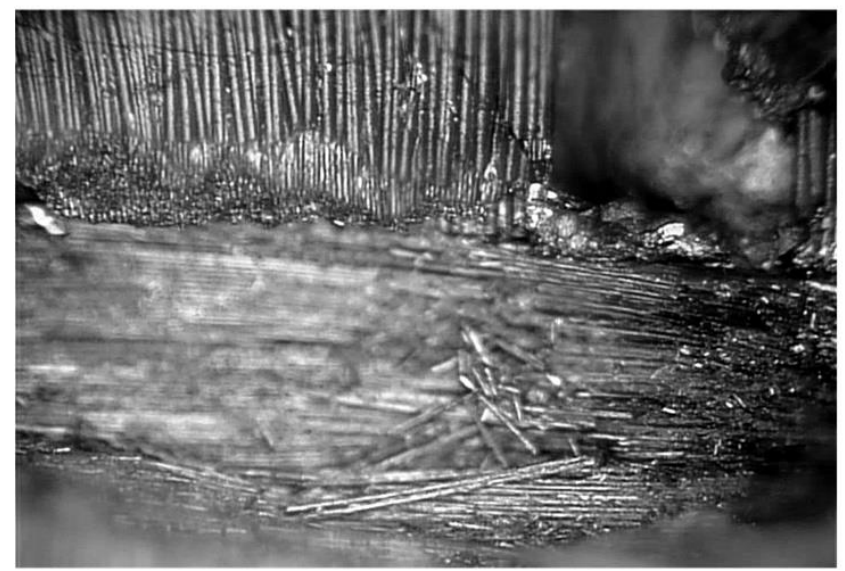

front side

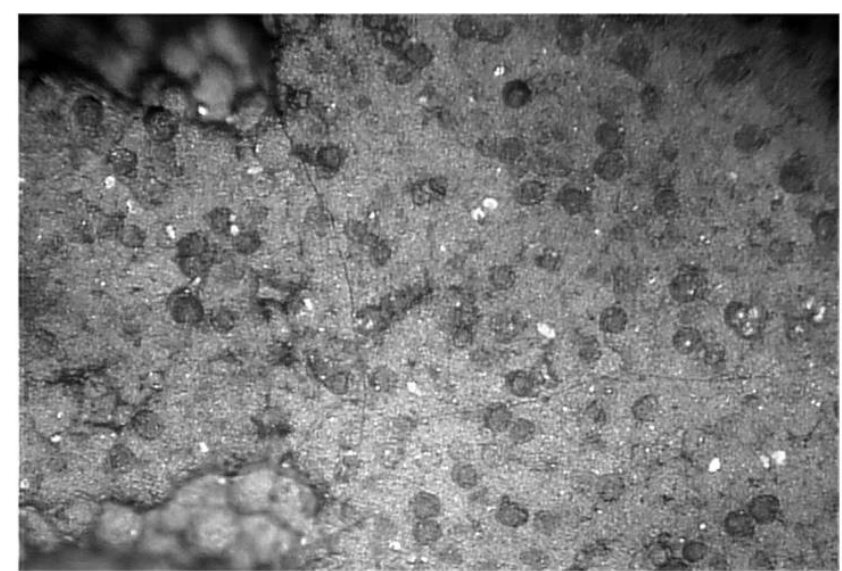

back side

(a)

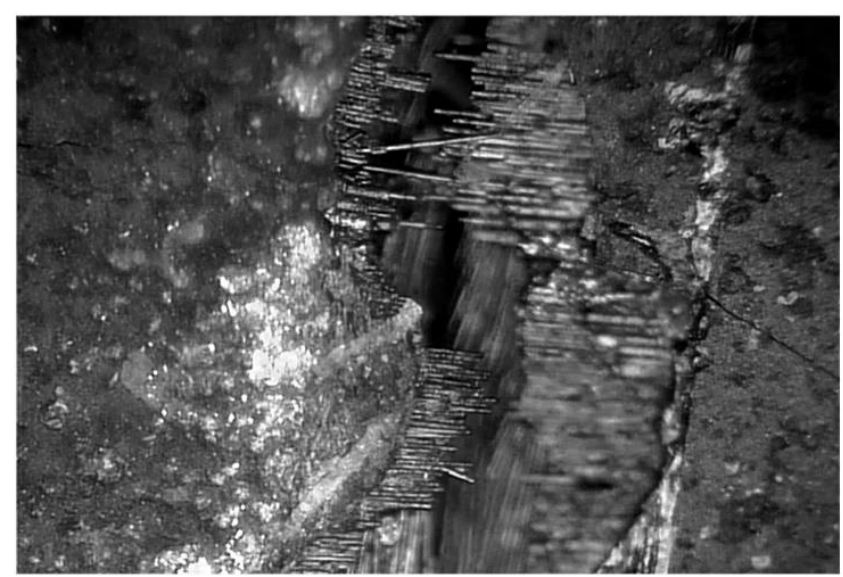

back side

(b)

Fig.4. Optical microscopic photography of impacting area $(350 \times)$ : (a) $1.0 \mathrm{~J}$; (b) $5.0 \mathrm{~J}$.

Fig. 5 illustrates the effect of impact energy on the coating damage of 2D C/SiC wherein impact energy values for the front, back and their total are plotted. There was nearly no damage produced when the impact energy was $0.5 \mathrm{~J}$. However, as the impact energy increases, it is observed that the damage area on the front side increase slightly, while the damage area on the back side increases very rapidly, especially, when the impact energy is greater than 2J. The reason is that the increasing flexural moment induced by the impact force may cause debonding and cracking over a large area, due to the low bonding strength between the coating and the laminate, as well as the weak fracture toughness of the SiC coating. 


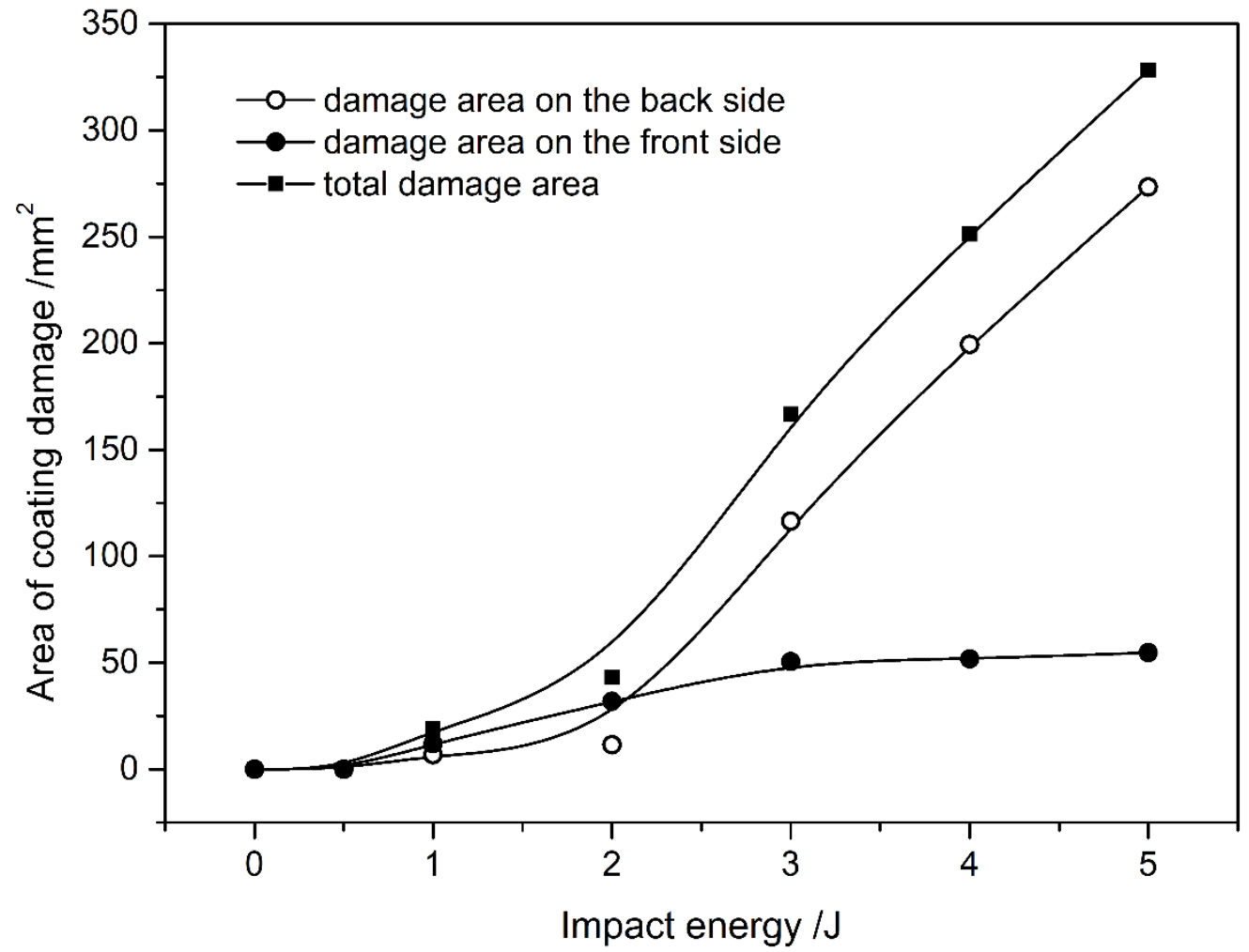

Fig.5. Damage areas of $\mathrm{SiC}$ coating after impact at various energy levels.

\subsection{Oxidation behavior after impact}

The isothermal oxidation curves of the as-received and impacted $\mathrm{SiC}$ coated $\mathrm{C} / \mathrm{SiC}$ in wet oxygen at $1300^{\circ} \mathrm{C}$ are shown in Fig. 6. For all specimens, increasing the oxidizing time increases the mass loss. Several chemical reactions are involved in the post-impact oxidation tests in the oxygen-water vapor mixture at $1300^{\circ} \mathrm{C}$, which are $[18,19]$ :

$$
\begin{array}{ll}
2 \mathrm{C}(\mathrm{s})+\mathrm{O}_{2}(\mathrm{~g}) \rightarrow 2 \mathrm{CO}(\mathrm{g}) & 5 \\
\mathrm{C}(\mathrm{s})+\mathrm{O}_{2}(\mathrm{~g}) \rightarrow \mathrm{CO}_{2}(\mathrm{~g}) & 6 \\
\mathrm{C}(\mathrm{s})+\mathrm{H}_{2} \mathrm{O}(\mathrm{g}) \rightarrow \mathrm{CO}(\mathrm{g})+\mathrm{H}_{2}(\mathrm{~g}) & 7 \\
\mathrm{SiC}(\mathrm{s})+3 / 2 \mathrm{O}_{2}(\mathrm{~s}) \rightarrow \mathrm{SiO}_{2}(\mathrm{~s})+\mathrm{CO}(\mathrm{g}) & 8 \\
\mathrm{SiC}(\mathrm{s})+3 \mathrm{H}_{2} \mathrm{O}(\mathrm{g}) \rightarrow \mathrm{SiO}_{2}(\mathrm{~s})+3 \mathrm{H}_{2}(\mathrm{~g})+\mathrm{CO}(\mathrm{g}) & 9
\end{array}
$$

The chemical reactions 5-7 involve the consumption of the carbon phase and result in mass loss and the degradation of mechanical performance. The reactions of $\mathrm{SiC}$ with $\mathrm{H}_{2} \mathrm{O}$ and $\mathrm{O}_{2}$ (Equation 8-9) lead to a mass increment. However, since the reactive velocity of carbon is much higher than that of $\mathrm{SiC}$, the weight of $\mathrm{C} / \mathrm{SiC}$ decreases with the oxidizing time. 


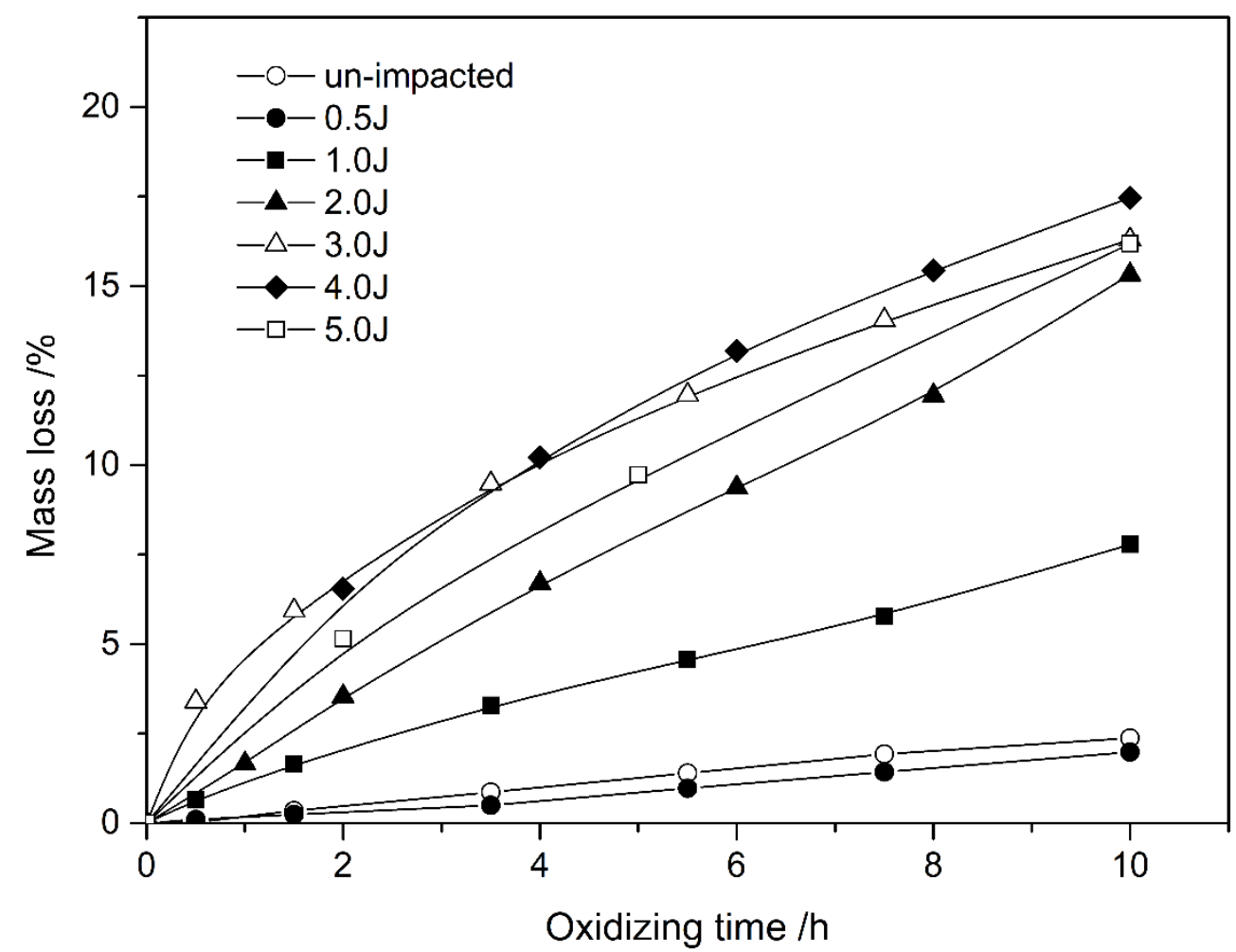

Fig.6. Isothermal oxidation curves of $\mathrm{SiC}$ coated $\mathrm{C} / \mathrm{SiC}$ in wet oxygen atmosphere at $1300^{\circ} \mathrm{C}$

According to previous studies, the oxidation kinetics of $\mathrm{C} / \mathrm{SiC}$ may be controlled by the diffusion of the oxidizing gas through the $\mathrm{SiC}$ coating cracks and the internal defects, as well as the chemical reactions between the components and the oxidizing gases [5]. If diffusion can provide enough oxidizing gas around carbon fibers, the oxidation of carbon will be determined by the chemical reaction rate, i.e., the oxidation is a reaction-controlled mechanism. Otherwise, the oxidation will be determined by the diffusive rate, i.e., the oxidation is a diffusion-controlled mechanism. Thus, the damage status of the coating after impact will define the primary oxidation mechanism of $\mathrm{C} / \mathrm{SiC}$.

Fig.7 illustrates the influence of the impact energy on the mass loss of $\mathrm{C} / \mathrm{SiC}$ after being oxidized for $10 \mathrm{~h}$. As a comparison, the mass loss of untreated uncoated $\mathrm{C} / \mathrm{SiC}$ is also indicated in Fig.7. The original unimpacted coating plays an excellent role in preventing oxidation of the carbon phases. The oxidizing gases can only enter the internal area through narrow cracks in the coating at a very low diffusive velocity, so oxidation of the carbon phases occurs very slowly. The resulting mass loss is therefore only $2.38 \%$. With the increasing impact energy, the evolution of mass loss can be divided into three intervals: (a) From 0 to $0.5 \mathrm{~J}$, the effect of the impact appears to be very limited. The mass loss is only $2.49 \%$ when the impact energy is $0.5 \mathrm{~J}$, nearly the same as the unimpacted specimen. (b) From $0.5 \mathrm{~J}$ to $2 \mathrm{~J}$, the mass loss shows a significant rise from $2.49 \%$ to $15.32 \%$. (c) From $2 \mathrm{~J}$ to $5 \mathrm{~J}$, the mass loss remains almost unchanged and close to the mass loss of uncoated $\mathrm{C} / \mathrm{SiC}$, which is $21.81 \pm 5.22 \%$. 


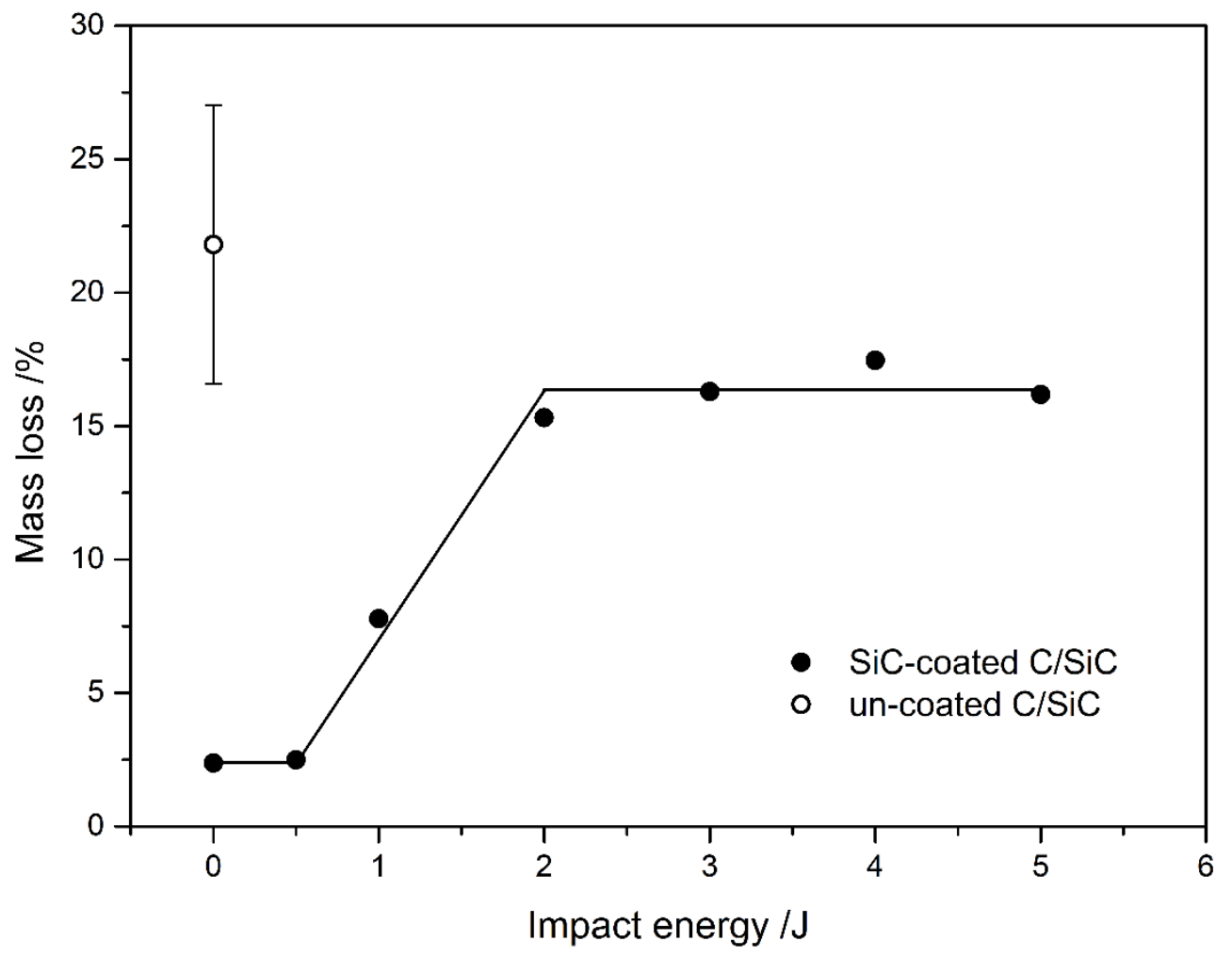

Fig.7. Influence of impact energy on mass loss after 10h oxidation

It is easy to understand that the oxidation behavior of $\mathrm{C} / \mathrm{SiC}$ depends on the coating damage conditions. Fig. 8 shows the relationship between the mass loss and the coating damage area. For the uncoated specimen, the coating damage area is defined to be twice that of the surface. Although a larger coating damage area allows more of the corrosive atmosphere to diffuse into the $\mathrm{C} / \mathrm{SiC}$, the mass loss doesn't always increase with the coating damage area. It is found from Fig. 8 that the effect of coating damage on oxidation behavior has two distinct stages. When the coating damage is less than $50 \mathrm{~mm}^{2}$, the oxidation rate significantly increases with the coating damage area. In this case, oxidation depends primarily on the rate of diffusion, i.e. the oxidation behavior is diffusion controlled. When the coating damage area is larger than $50 \mathrm{~mm}^{2}$, the coating damage area has little effect on the oxidation behavior. Since oxygen can diffuse into the internal area freely, the oxidation of $\mathrm{C} / \mathrm{SiC}$ becomes reaction controlled. 


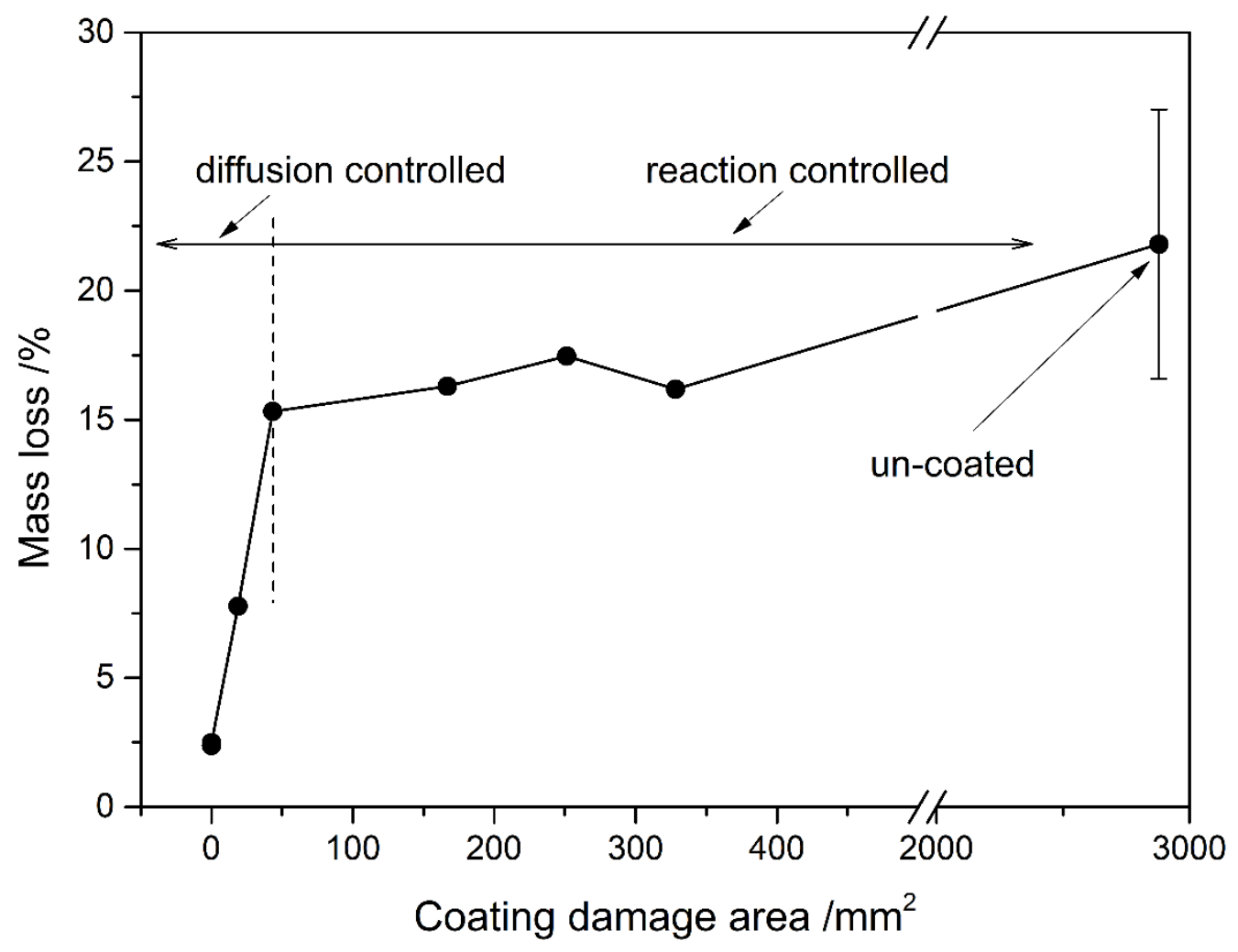

Fig.8. Relationship between mass loss and coating damage area

Mass loss of $\mathrm{C} / \mathrm{SiC}$ is the result of the oxidation of carbon fibers. Fig. 9 shows the SEM microstructure of fracture surfaces. It can be seen from Fig. 9 that the extension of the oxidation of carbon fibers is greatly different under different impact energies. For the $0.5 \mathrm{~J}$ specimen, the oxidation occurs locally, with only a few fibers in the first ply next to the SiC coating becoming oxidized (Fig. 9(a)). Some short fiber pull-out in the central region may be observed, and the fiber tips are round, which indicates that the internal fibers are maintained in their original condition (Fig. 9(b)). For the 1J specimen, carbon fibers near the surface were completely oxidized extensively and only SiC tubes were left (Fig. 9(c)). However, in the central area, it was deduced from observing some thin and sharp pull-out fibers (Fig. 9(d)) that the fibers were partially slightly oxidized. For the 5J specimen, the carbon fibers are nearly totally oxidized in the area near to the surface (Fig. 9(e)), as well as in the central region (Fig.9(f)). 

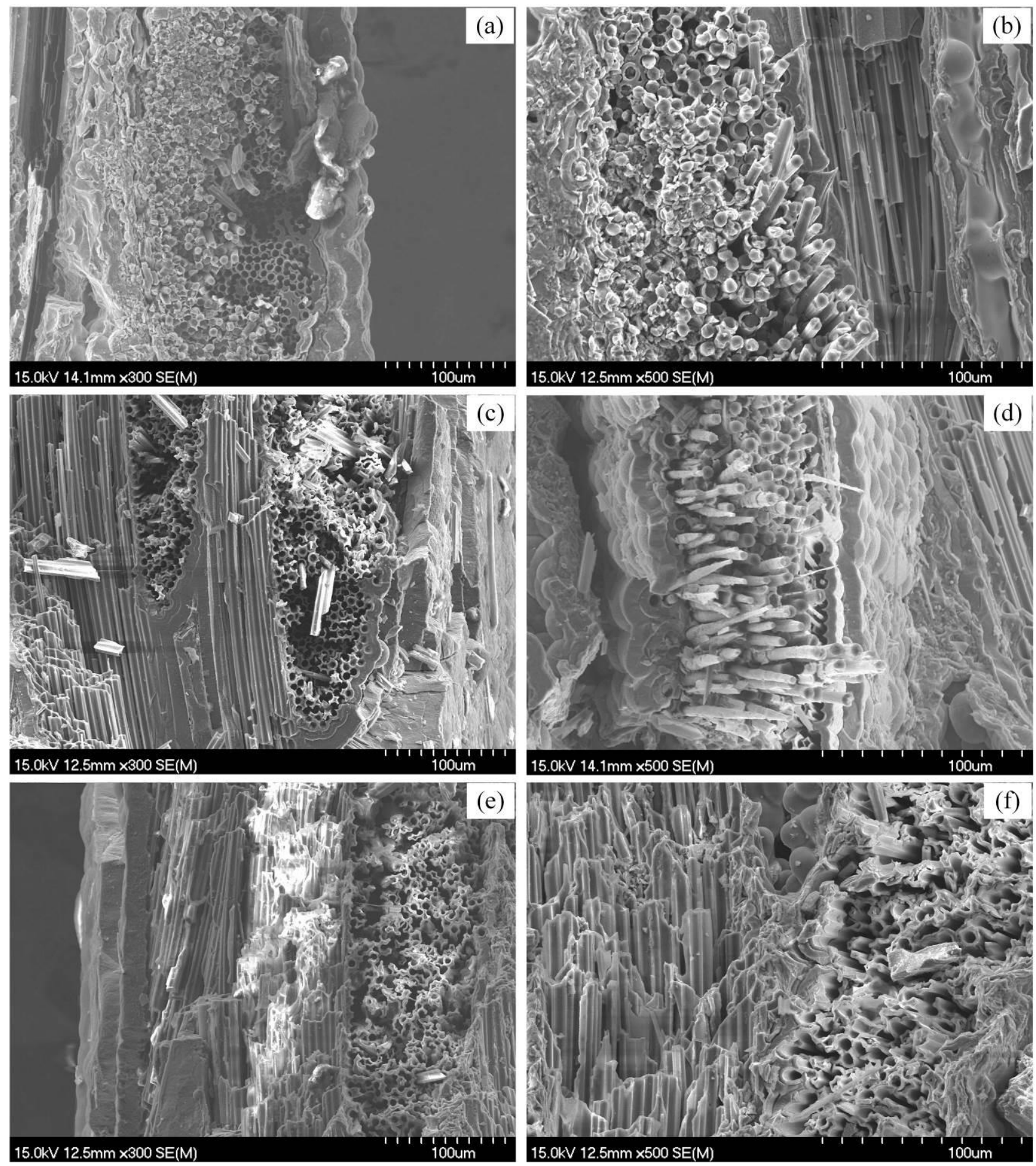

Fig. 9. Fracture surfaces near the coating and at interior of SiC-coated 2D C/SiC after impact and oxidation: (a) and (b) $0.5 \mathrm{~J},(\mathrm{c})$ and (d) $1 \mathrm{~J},(\mathrm{e})$ and (f) $5 \mathrm{~J}$.

\subsection{Residual flexural properties}

The flexural load-displacement curves of the oxidized C/SiC are shown in Fig. 10. As the main load-carrying phase, the oxidation of carbon fibers will inevitably lead to a degradation in the mechanical properties of the material. The mass percentage of carbon fibers can be calculated by:

$$
M_{\mathrm{C}}=\frac{\rho_{\mathrm{C}} V_{\mathrm{C}}}{\rho_{\mathrm{C}} V_{\mathrm{C}}+\rho_{\mathrm{SiC}} V_{\mathrm{SiC}}} \times 100 \%
$$

where $M_{C}$ is the fiber mass percentage, $\quad \rho_{\mathrm{C}}$ and $\rho_{\mathrm{SiC}}$ are the mass density of carbon fiber and $\mathrm{SiC}$ respectively, and $V_{C}$ 
and $V_{S i C}$ are the fiber volume percentage and mass volume percentage respectively. It can be calculated using Eq, 10 that the fiber mass percentage of untreated $\mathrm{C} / \mathrm{SiC}$ is $32.84 \%$. Since the oxidation speed of the $\mathrm{SiC}$ matrix is much slower than carbon fiber, the percentage of fiber oxidation $\Delta m_{C}$ can be determined by the ratio of the mass loss percentage to the fiber mass percentage, i.e.,

$$
\Delta m_{C}=\frac{\Delta m}{M_{\mathrm{C}}} \times 100 \%
$$

The percentage of fiber oxidation, flexural strength and the strength retention ratio of the oxidized $\mathrm{C} / \mathrm{SiC}$ under the LVI at various impact energies are listed in Table 1 and illustrated in Fig. 11. For unimpacted and impacted cases under $0.5 \mathrm{~J}$, only about $7 \%$ of the fibers are oxidized. Less fiber oxidation means that the mechanical properties are largely maintained. The flexural strength is about $280 \mathrm{MPa}$, which is $93 \%$ of the non-oxidized specimen. With the increase in the impact energy, more fibers are oxidized and the flexural strength decreases rapidly. If the impact energy is larger than $2 \mathrm{~J}$, half of the carbon fibers are oxidized. Since the oxidation process starts from the impact damage area, it is believed that the fiber preform around the impact contacting region has been totally destroyed. So, the flexural load is carried by the $\mathrm{SiC}$ matrix, and the strength retention ratio is less than $8 \%$, indicating that coating totally loses its intended function.

Table 1. Percentage of fiber oxidation, flexural strength, and strength retention ratio of oxidized C/SiC under LVI

\begin{tabular}{|c|c|c|c|}
\hline Impact energy $(\mathrm{J})$ & $\Delta m_{C}(\%)$ & Flexural strength (MPa) & Strength retaintion ratio (\%) \\
\hline $0^{*}$ & 0 & 351.14 & 81.09 \\
\hline 0 & 7.25 & 284.75 & 79.47 \\
\hline 0.5 & 7.58 & 279.06 & 36.90 \\
\hline 1 & 23.68 & 129.56 & 7.46 \\
\hline 2 & 46.65 & 26.20 & 6.55 \\
\hline 3 & 49.62 & 23.01 & 6.50 \\
\hline 4 & 53.18 & 22.83 & 5.23 \\
\hline 5 & 49.28 & 18.38 & \\
\hline
\end{tabular}

* non-oxidized $\mathrm{C} / \mathrm{SiC}$ 


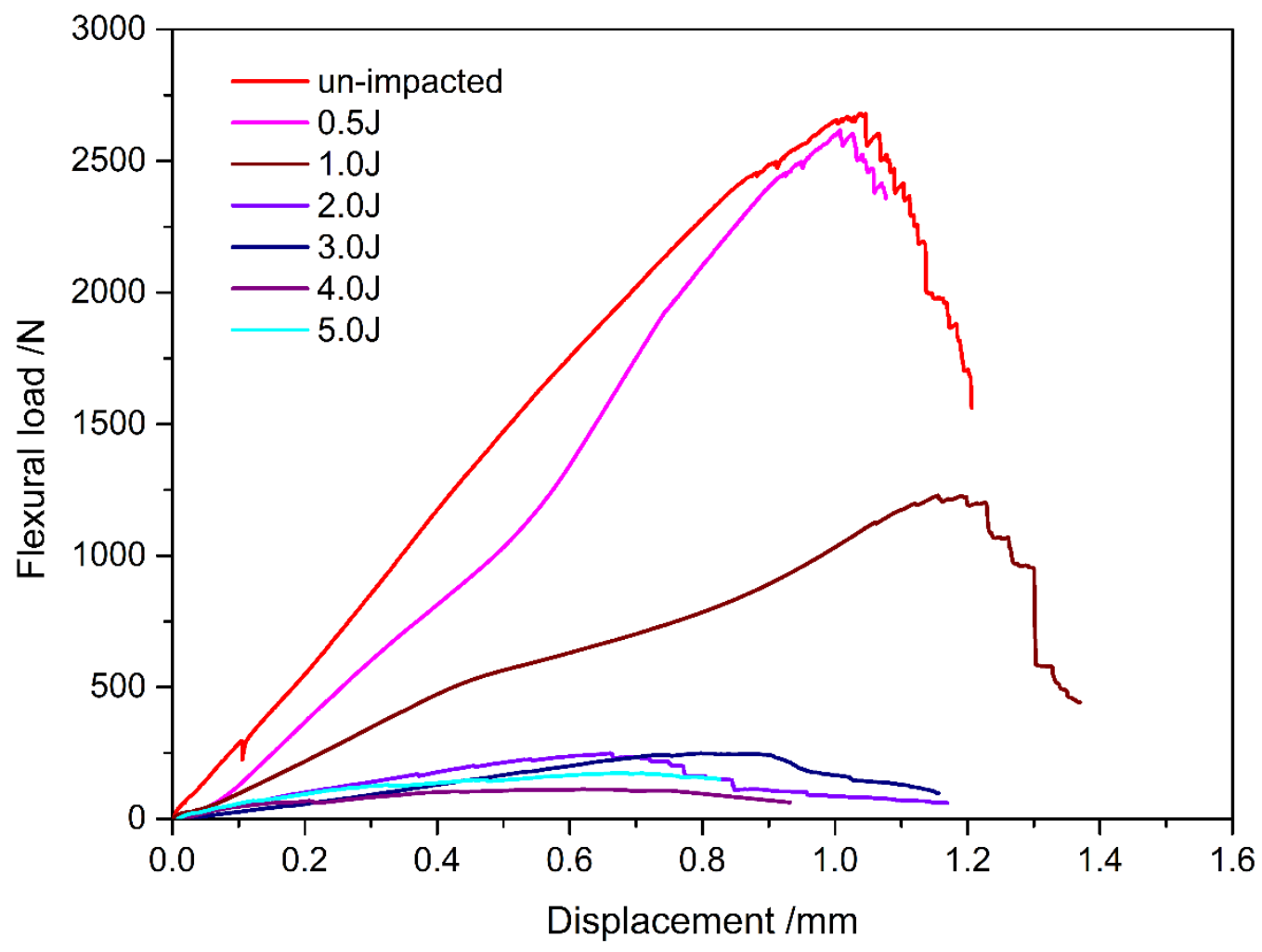

Fig. 10. Flexural load-displacement curves of oxidized $\mathrm{C} / \mathrm{SiC}$ specimens.

Percentage of fiber oxidation $/ \%$

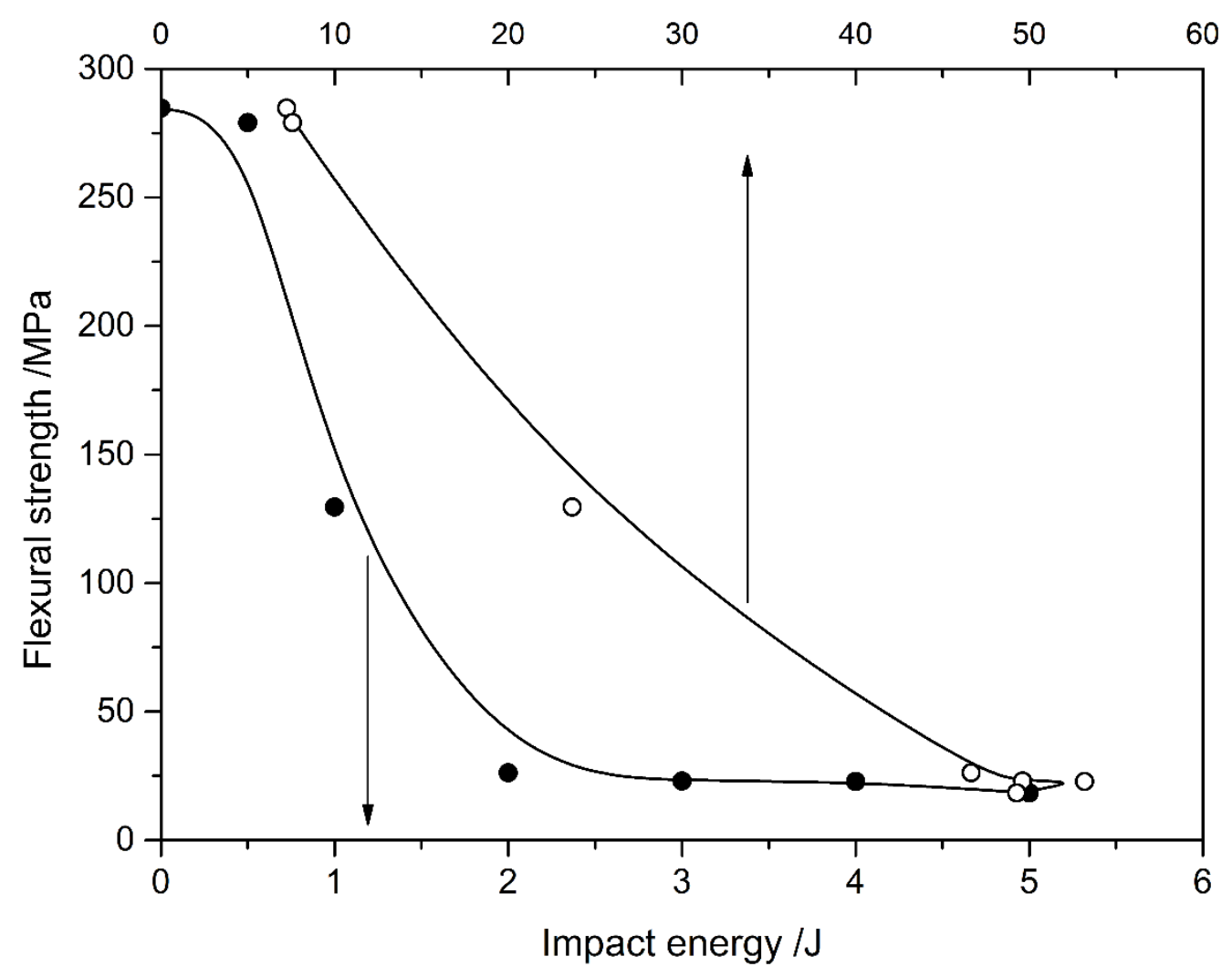

Fig. 11. Relationship of the residual flexural strength with the impact energy and the percentage of fiber oxidation. 


\section{Conclusions}

Low velocity impact has a significant effect on the anti-oxidation properties of $\mathrm{SiC}$ coated plain-woven $\mathrm{C} / \mathrm{SiC}$ composites. The impact energy corresponding to coating damage initiation was $0.5 \mathrm{~J}$, where the oxidation loss was $2.49 \%$ and the strength retention ratio was $79.47 \%$, almost the same with the as-received coating. The coating damage area increased rapidly with an increase in impact energy. Correspondly, the oxidation mechanism gradually changed from a primarily diffusion-controlled local oxidation to a reaction-controlled uniform oxidation, with a critical point around $2 \mathrm{~J}$. Once the impact energy was larger than $2 \mathrm{~J}$, half of the carbon fibers were oxidized in the oxidation test and the residual strength was no more than $8 \%$ of the non-oxidized $\mathrm{C} / \mathrm{SiC}$, indicating that coating totally losed its anti-oxidation function.

\section{Acknowledgements}

This work has been financially supported by the National Natural Science Foundation of China (51772244 and 11072195).

\section{References}

[1] Naslain R. SiC-matrix composites: non-brittle ceramics for thermo-structural application. Int J Appl Ceram Technol $2005 ; 2: 75-84$.

[2] Naslain R. Design, preparation and properties of non-oxide CMCs for application in engines and nuclear reactors: an overview. Compos Sci Technol 2004; 64:155-170.

[3] Schmidt S, Beyrer S, Knabe H, Immich H, Gessler A. Advanced ceramic matrix composite materials for current and future propulsion system applications. Acta Astronautica 2004; 55:409-420.

[4] Xiang Y, Chen ZH, Cao F. High-temperature protective coatings for C/SiC composites. J Asian Ceram Soc 2014; 2:305-309.

[5] Cheng LF, Xu YD, Zhang LT, Yin XW. Oxidation behavior from room temperature to $1500^{\circ} \mathrm{C}$ of 3D-C/SiC composites with different coatings. J Am Ceram Soc 2002; 85:989-991.

[6] Xiang Y, Li W, Wang S, Chen ZH. Oxidation behavior of oxidation protective coatings for PIP-C/SiC composites at $1500^{\circ}$ C. Ceram Int 2012; 38: 9-13.

[7] Wu SJ, Cheng LF, Zhang LT, Xu YD. Oxidation behavior of 2D C/SiC with a multi-layer CVD SiC coating. Surface \& Coatings Technol 2006; 200:4489-4492.

[8] Yin XW, Cheng LF, Zhang LT, Xu YD, Li JZ, Oxidation behavior of 3D C/SiC composites in two oxidizing environments. Compos Sci Technol 2001; 61:977-980.

[9] Yin XW, Cheng LF, Zhang LT, Xu YD, Luan XG. Oxidation behaviour of three-dimensional woven C/SiC composites, Mater Sci Technol 2001; 17:727-730.

[10] Yin XW, Cheng LF, Zhang LT, Xu YD. Oxidation behaviors of $\mathrm{C} / \mathrm{SiC}$ in the oxidizing environments containing water vapor. Mater Sci Engng A 2003; 348:47-53.

[11] Yao LJ, Feng ZY, Cheng QY. Low velocity impact damage evaluation of 2D C/SiC composite material. Adv Mater Res 2009; 79-82:1835-1838.

[12] Mei H, Yu CK, Xu HR, Cheng LF. The effects of stitched density on low-velocity impact damage of cross-woven carbon fiber reinforced silicon carbide composites. Ceram Int 2016; 42:1762-1768.

[13] Mei H, Yu CK, Xu YW, Han DY, Cheng LF. Effect of impact energy on damage resistance and mechanical property of C/SiC composites under low velocity impact. Mater Sci Engng A 2017; 687:141-147.

[14] Herb V, Martin E, Couégnat G. Damage analysis of thin 3D-woven $\mathrm{SiC} / \mathrm{SiC}$ composite under low velocity impact loading. Compos Part A 2012; 43:247-253.

[15] Trabandt U, Esser B, Koch D, Knoche R, Tumino G. Ceramic matrix composites life cycle testing under reusable launcher environmental conditions. Int J Appl Ceram Technol 2005; 2:150-161.

[16] Srivastava VK, Maile K, Klenk A. Effect of impact damage on flexural strength of C/C-SiC composites, Mater Sci Engng $A$ 2003; 271:38-42.

[17] Srivastava VK, Maile K, Bothe K, Udoh A. Effect of damage on flexural modulus of C/C-SiC composites, Mater 
Sci Engng A 2003; 354:292-297.

[18] Lamouroux F, Naslain R, Jouin JM. Kinetics and mechanisms of oxidation of 2D woven C/SiC composites: II, theoretical approach. J Am Ceram Soc 1994; 77:2058-2068.

[19] Filipuzzi L, Gamus G, Naslain R. Oxidation Mechanisms and Kinetics of 1D-SiC/C/SiC Composite Materials: II, Modeling. J Am Ceram Soc 1994; 77:467-80. 